ESTUDOS LINGÜÍSTICOS 


\title{
SEMÂNTICA FORMAL
}

\author{
José Borges Neto*
}

\section{A problemática do significado ${ }^{1}$}

eralmente, define-se a semântica como "o estudo do significado". Esta definição, na medida em que assume que o termo significado é unívoco e que o conceito associado é claro, cria mais problemas do que resolve. A definição, na realidade, deixa-nos com o espinhoso problema de dizer o que é o significado, antes de dizermos o que é a semântica, que o estuda.

Infelizmente, os significados não são objetos que possamos ver, cheirar, apalpar; os significados não estão no contínuo espaço-tempo, de forma a podermos observá-los, medi-los, como fazemos com os objetos, digamos, "físicos". Os significados são objetos teóricos, construções dos lingüistas. Não quero dizer com isso que os significados não existam (o que quer que eles sejam); quero apenas dizer que frente a alguns fenômenos mais ou menos óbvios as pessoas dizem coisas com a linguagem e compreendem coisas quando diante de expressões linguiísticas; cabe aos teóricos "criar", "construir", um elemento

* Universidade Federal do Paraná.

1 Texto base da aula proferida como prova didática no concurso para professor titular de Linguiistica no DLLCV/UFPR (27 de agosto de 1998). 
de explicação e uma das possibilidades é postular a existência de alguma coisa que se denomine "significado".

Essa natureza teórica dos significados faz com que todas as teorias não sejam mais do que hipóteses sobre o funcionamento de uma parte (essencial, não obstante) da linguagem humana. E será sobre algumas dessas hipóteses que falaremos a seguir.

A primeira distinção a ser feita diz respeito ao lugar onde buscar os significados. Ao observar as várias teorias do significado disponíveis na praça, vemos que elas se dividem em dois grupos: teorias que localizam o significado na própria linguagem e teorias que localizam o significado nos falantes (no falante, em sentido estrito, ou no ouvinte). As teorias do primeiro grupo consideram que a linguagem significa; as teorias do segundo grupo consideram que os falantes significam com a linguagem.

É lícito afirmar, diante dos fenômenos, que ambas as posições têm sua dose de razão: as expressões lingüísticas significam "coisas" e os falantes dizem "coisas" com as expressões lingüísticas. O interessante é que o significado das palavras e o significado dos falantes não precisa coincidir. É possível encontrar casos em que o falante $\mathrm{A}$ diz $\mathrm{X}$ com as palavras $\mathrm{P}$ embora as palavras $\mathrm{P}$ "costumem" significar Y para os outros falantes. Alguém pode, por exemplo, mandar o outro calar a boca dizendo "parece que vai chover" (imagine-se a situação em que o falante A está falando mal de B e um parente de B se aproxima; um falante C, com a enunciação de "parece que vai chover" pode estar indicando a A que é melhor mudar de assunto). Apesar disso, o senso comum parece indicar que a expressão "parece que vai chover" tem um significado próprio, "literal", independente do falante e do contexto de uso.

A primeira grande questão que o estudioso da semântica enfrenta, então, é a da escolha entre incluir o significado do falante ou não. Nesse momento, gostaria de estabelecer uma primeira distinção terminológica, que, como todas as distinções terminológicas, resulta de uma visão particular do objeto: vou tratar por semântica apenas as teorias que tratam do significado das expressões lingüísticas. Os significados dos falantes serão tratados em outra disciplina: a pragmática.

Na verdade, a questão não se resolve tão facilmente assim e certamente precisarei voltar a esse assunto em outro momento.

Pois bem. Ficando só com as teorias que tratam dos significados das expressões lingüísticas, podemos novamente agrupá-las em dois conjuntos: o conjunto das teorias que tratam o significado como uma espécie de entidade e o conjunto das teorias que tratam o significado como uma relação. Comecemos com o primeiro conjunto. 
Encontramos, teoricamente, dois tipos de teorias que tratam o significado como uma entidade: as teorias referenciais $\mathrm{e}$ as teorias ideacionais.

Tanto teorias que tomam o significado como o objeto que a expressão lingüística refere (teorias referenciais do significado), quanto teorias que assumem que o significado é um conceito, ou uma idéia, que reside na mente das pessoas (teorias ideacionais do significado) vão ter problemas sérios ao tentar dar conta de preposições, conjunções, artigos, etc., que certamente são expressões com significado mas que não apresentam referente claro, nem se associam claramente a conceitos.

Dizer que o significado de uma expressão é a "coisa" que a expressão refere só é razoável quando tratarmos de expressões que designam objetos (a circularidade é óbvia: todas as expressões que "significam" objetos têm objetos como seu significado). Se tratamos de nomes próprios (Pedro, Curitiba, etc.), de nomes comuns concretos (mesa, pedra, livro, etc.) e de adjetivos qualificativos que designam atributos físicos de objetos (vermelho, alto, gordo, etc.), temos a impressão de que a abordagem referencial se sustenta; por outro lado, diante de nomes abstratos, como "liberdade", "democracia" ou "amor", por exemplo, assumirmos que o significado é o objeto referido já não parece ser mais tão razoável.

Considerar, alternativamente, que os significados são entidades mentais não melhora em nada a situação da teoria semântica. Em primeiro lugar, porque conhecemos muito pouco sobre o funcionamento das mentes, e é pura especulação dizer que lá existem coisas que podem ser chamadas de significados (há até quem duvide da existência da própria mente). Em segundo lugar, e principalmente, porque não temos acesso ao conteúdo das outras mentes (talvez nem mesmo das nossas próprias), o que impede qualquer abordagem minimamente objetiva do significado. Em outras palavras, dada a concepção ideacional, a construção de uma ciência do significado torna-se difícil, se não impossível. $O$ que não quer dizer que não possamos falar de significados assim concebidos: uma abordagem ideacional pode ser bastante interessante e podemos, com ela, aprender muito sobre a linguagem e os seus usuários (a psicanálise está aí para demonstrar isso).

O procedimento corrente, então, é considerar que o significado é uma espécie de relação, e não uma entidade. Boa parte dos lingüistas concorda que o significado de uma expressão poderia ser a relação que se estabelece entre a expressão e algo não-lingüistico. Infelizmente, o problema de definir a natureza dos significados permanece. Por exemplo, para alguns o significado seria a relação que se dá entre as expressões lingüísticas e o mundo externo que as expressões descrevem (abordagem conhecida como semântica de valor de 
verdade e que é a contraparte "relacional" das teorias referenciais do significado); para outros, o significado é a relação entre as expressões e algo equivalente aos conceitos mentais propostos pela teoria ideacional do significado (as chamadas representações semânticas), resultando na contraparte relacional de tal teoria.

Quanto à contraparte relacional das teorias ideacionais (algo que pode ser chamado de "semântica cognitiva", como fez Jackendoff em 1983, além da questão do recurso à noção de mente e de seus conteúdos, a principal crítica que se poderia fazer é que, no final, será preciso explicar como as representações semânticas (que são entidades mentais) se relacionam com os estados de coisas do mundo, a menos que a teoria se pretenda completamente anti-realista. Se assumirmos que existe um mundo fora de nossas mentes, que não é inteiramente construído por nós, e se assumirmos que, de algum jeito, a linguagem é capaz de falar desse mundo, não vejo como é possível falar em representações semânticas sem dizer o que essas "representações" representam. Em suma, essa abordagem "cognitiva" dos significados, embora possa resolver alguns problemas presentes nas teorias de valor de verdade, só adia, na verdade, o problema de se estabelecer uma relação sistemática entre a linguagem e o mundo.

Muito mais interessante, então, é a proposta da semântica de valor de verdade. Antes de abordá-la, no entanto, creio necessária uma breve passagem por um conjunto de propostas que consideram que o significado é a relação que se dá entre as expressões linguíísticas e o uso que os falantes fazem delas.

Em primeiro lugar, creio que existem várias vertentes dessa posição, que podem, no entanto, ser agrupadas em dois conjuntos.

No primeiro conjunto eu colocaria todas as propostas que defendem que os significados resultam dos usos das expressões e constituem algo como um "reflexo" desses vários usos. Um defensor dessa posição diria coisas como "o significado de uma expressão é o somatório dos vários usos que essa expressão já teve em sua história".

O que precisa ficar claro, aqui, é que, de algum jeito, essas propostas acabam por concluir que as expressões têm significado, embora esses significados não sejam nem estáveis (estabelecidos de uma vez por todas) nem completamente independentes da "ideologia" (num sentido amplo) dos falantes (de uma "formação discursiva", como poderíamos dizer, do ponto de vista de uma outra abordagem). Ou seja, trata-se de propostas semânticas.

O segundo conjunto, por sua vez, agruparia as propostas dos que defendem que o significado se dá no uso das expressões e que, portanto, fora da situação de uso as expressões "não significam". Deste ponto de vista, as expressões "só significam" no uso efetivo. 
Ora, quer me parecer que há dois modos de entender as propostas desse segundo conjunto: ou se está dizendo que as expressões são semanticamente indeterminadas, e isso não leva necessariamente à afirmação de que não existe significado prévio aos atos de fala, ou se está implicando que a cada momento, em cada ato de fala, a linguagem está sendo novamente inventada. A questão da indeterminação semântica pode ser tratada por outras propostas (inclusive por uma semântica de valor de verdade, como veremos). A suposição de que as expressões colocadas em cena num ato de fala concreto não trazem nenhum "conteúdo" a esse ato de fala, nenhum significado previamente estabelecido, me parece completamente absurda e insustentável.

O conjunto de propostas que defendem a idéia de que o significado das expressões é resultado de uma história (ou de uma formação discursiva) é, certamente, mais interessante e não posso deixar de explorá-lo.

Antes de seguir adiante, no entanto, gostaria de chamar em meu auxílio uma distinção, relativamente recente, levantada por Hintikka. Trata-se da distinção "linguagem como cálculo" versus "linguagem como meio universal".

\section{"Linguagem como cálculo" versus "linguagem como meio universal"}

Num trabalho de 1979, Jaakko Hintikka propõe a distinção "linguagem como cálculo" versus "linguagem como meio universal", que traz inúmeras conseqüiências para a semântica. Nas palavras de Hintikka:

A característica mais geral em que posso pensar para a primeira perspectiva [linguagem como meio universal] é que, de acordo com ela, nós não podemos 'sair' de nossa linguagem, como se a olhássemos de fora. A razão é que os resultados de todas essas 'visadas' deveriam ser exprimíveis em nossa linguagem. Ora, essa linguagem pressupōe em todos os seus usos certas relações semânticas (relações de representação) entre a linguagem e a realidade (de outra forma não poderíamos usar a linguagem em nossas transaçōes com a realidade). Mas, desde que essas relações semânticas estão pressupostas em todo e qualquer uso da linguagem, elas não podem ser expressadas na linguagem. Qualquer tentativa de fazer isso vai envolver circularidade e fatalmente resultar em contradição (nonsense) ou em tautologia. (p. 716) 
Em outras palavras, se assumirmos a perspectiva "linguagem como meio universal", as relações semânticas não podem ser ditas. Na melhor das hipóteses, podem ser mostradas. Da mesma forma, na medida em que a linguagem é o meio universal, todas as considerações metalingüísticas ficam excluídas.

Por outro lado, assumida a perspectiva "linguagem como cálculo", entre outras coisas, podemos pensar nessas relações de representação entre a linguagem e o mundo (nessa semântica) como sujeitas a uma variação em larga escala. A linguagem se interpreta num modelo e os modelos são infinitos. Como diz Hintikka: "A utilização do termo calculus aqui não pretende comparar a linguagem a um cálculo não-interpretado, um mero jogo com símbolos characterers, mas enfatizar que a linguagem, incluindo a nossa língua materna, é em princípio livremente reinterpretável como um cálculo, ao menos para os propósitos de um semanticista." (p. 717)

Em outras palavras, as expressões lingüísticas não têm um significado "inerente", nem se acredita, como faz o defensor da perspectiva "linguagem como meio universal", numa série fixa universal de relações de sentido entre linguagem e mundo. As expressões lingüísticas são "vazias" ("indeterminadas") e adquirem seu significado na relação com um modelo.

A inefabilidade da semântica, consequiência da perspectiva "linguagem como meio universal", vai forçar os adeptos dessa perspectiva a se restringirem às relações sistemáticas que se podem estabeleccr entre os signos (relações sintáticas, portanto) e à utilização desses signos pelos falantes nos processos de comunicação, argumentação, etc. (à pragmática, portanto). É corolário da perspectiva "linguagem como meio universal" que os estudos da linguagem devem restringir-se à sintaxe e à pragmática. A semântica, entendida como o relacionamento sistemático de expressões de uma linguagem e "o nãolingüístico", só é possível no quadro da perspectiva "linguagem como cálculo".

Se a postura "linguagem como meio universal" considera que a semântica é inacessível, não podemos, em seu interior, conceber sistemas diferentes de relações semânticas e, portanto, a teoria de modelos e a noção de mundos possiveis devem ser rejeitadas, levando-nos à aceitação do relativismo lingüístico. A metalinguagem é um uso irregular da linguagem, e a idéia de verdade como correspondência é na melhor das hipóteses inexplicável e talvez mesmo ininteligível.

Se, por outro lado, assumirmos a postura "linguagem como cálculo", a semântica é possível e devemos admitir a possibilidade de diferentes sistemas de relações semânticas. A teoria de modelos e a noção de mundos possíveis passam a ser inteligíveis e o relativismo lingüístico pode ser rejeitado. A 
metalinguagem é possível e legítima, e a idéia de verdade como correspondência é inteligível.

Em síntese, as duas posturas se distinguem principalmente pelas possibilidades de interpretação da linguagem que admitem: a posição "linguagem como cálculo" assume que uma língua é um sistema que pode ser livremente reinterpretado, enquanto a posição "linguagem como meio universal" assume que uma língua não pode ser desvinculada de sua interpretação única.

Acredito que a posição que considera que o significado das expressões só se estabelece no uso efetivo (a proposta que rejeitei há pouco) acaba por ter que assumir, simultaneamente, que a linguagem é meio universal. Em consequiência, deverá negar a possibilidade da semântica. Os defensores dessa posição devem substituir a semântica pela pragmática e a teoria do significado por uma teoria da ação.

Embora eu não me sinta capaz de argumentar no sentido da rejeição da perspectiva "linguagem como meio universal" (defendida por gigantes do porte de um Wittgenstein), sinto-me suficientemente justificado em não escolhê-la para fazer semântica das línguas naturais.

Fiquemos então com a perspectiva "linguagem como cálculo", e 'dentro dela' com a posição de que o significado se estabelece na relação entre as expressões linguísticas e o mundo (um modelo do mundo, para ser mais preciso). Vamos assumir aqui a chamada teoria da correspondência.

\section{Teoria da correspondência}

A noção de verdade é fundamental para que possamos estabelecer as relações entre a linguagem e os modelos de mundo. Vamos assumir aqui a formulação de Tarski para a questão da verdade.

A "fonte" da teoria tarskiana da verdade é Aristóteles, que na sua Metafísica faz a seguinte afirmação (uma pequena jóia do senso comum): "Dizer do que é que não é, ou do que não é que é, é falso, enquanto dizer do que é que é, ou do que não é que não é, é verdadeiro." (apud Tarski, 1972, p. 12.).

Essa concepção aristotélica de verdade (formulada como "A verdade de uma sentença consiste em seu acordo (ou correspondência) com a realidade.") vai dar origem à concepção semântica da verdade de Tarski e à sua famosa "convenção (T)". O raciocínio de Tarski é o seguinte: Consideremos a sentença "A neve é branca" e perguntemos em que condições essa sentença é verdadeira ou falsa. Se assumirmos a concepção aristotélica de verdade, a resposta é óbvia: a sentença será verdadeira se a neve é branca e será falsa se a neve não é branca. 
Em outras palavras, se eu afirmo que a neve é branca e a neve é, de fato, branca, a afirmação é verdadeira; se eu afirmo que a neve não é branca mas a neve é branca, a afirmação será falsa. Assim, vamos obter a seguinte equivalência:

(1) A sentença "a neve é branca" é verdadeira se, e apenas se, a neve é branca.

Note-se que a sentença "a neve é branca" aparece duas vezes na equivalência: uma vez, entre aspas, no primeiro membro da equivalência e outra vez, sem aspas, no segundo membro. Segundo Tarski, no segundo membro da equivalência temos a própria sentença, enquanto no primeiro membro temos o seu nome.

Generalizando o procedimento, Tarski propõe que se tome uma sentença qualquer, se substitua esta por uma variável sentencial p e que se atribua um nome à sentença, representado pela variável $\mathrm{X}$, obtendo-se a seguinte equivalência, chamada equivalência da forma $(T)$ :

(T) $X$ é verdadeira se, e apenas se, $p$.

Consciente de que sua formulação da concepção semântica da verdade pode levar a paradoxos, como o do mentiroso, por exemplo, Tarski apresenta duas restrições: (i) que sua proposta não vale para as linguagens semanticamente fechadas; e (ii) que é preciso sempre usar duas linguagens: a linguagem-objeto e a metalinguagem. Vamos refazer, rapidamente, o raciocínio de Tarski.

Em primeiro lugar, vejamos a formulação que Tarski dá ao paradoxo do mentiroso. Consideremos a sentença (2):

(2) A sentença (2) não é verdadeira.

Para abreviar, a sentença (2) será representada pelo símbolo ' $S$ '.

De acordo com a convenção de Tarski, é possível afirmar a seguinte equivalência da forma $(\mathrm{T})$ :

(T) $S$ é verdadeira se, e apenas se, a sentença (2) não é verdadeira.

Levando-se em conta o significado do símbolo ' $S$ ', pode-se estabelecer empiricamente o seguinte fato:

(3) S é idêntica à sentença (2).

Agora, pela lei de Leibniz, poderíamos substituir a expressão "a sentença (2)" pelo símbolo ' $S$ ', em (T'). Só que assim obteríamos uma contradição evidente:

(4) $S$ é verdadeira se, e apenas se, $S$ não é verdadeira.

Analisando as suposições que conduzem ao paradoxo do mentiroso, Tarski observa que: (i) supõe-se que na linguagem em que se constrói o paradoxo estão contidos, além das expressões próprias, os nomes das expressões e termos semânticos como "verdadeiro" e "falso", atribuídos a sentenças da linguagem. Supõe-se também que todas as orações que determinam o uso adequado desses 
termos semânticos podem ser ditas na linguagem; (ii) supõe-se que as leis ordinárias da lógica valem para essa linguagem; e (iii) supõe-se que podemos formular e afirmar em nossa linguagem premissas empíricas como "'S' é idêntica à sentença (2)".

Tarski vai chamar qualquer linguagem que apresente a propriedade (i) de linguagem semanticamente fechada.

Ora, segundo Tarski, a suposição (iii) não é essencial para a derivação do paradoxo, mas as suposições (i) e (ii) são: toda linguagem que satisfaz a essas duas suposições é inconsistente. É necessário, então, recusar ao menos uma delas. Certamente, Tarski não vai propor a recusa da suposição (ii). Resta, assim, a possibilidade de recusa da suposição (i).

Sua decisão será a de não usar linguagem alguma que seja semanticamente fechada. O que equivale a recusar, de saída, a possibilidade de entender a linguagem como meio universal. Para não usar linguagens semanticamente fechadas, a saída de Tarski é sempre usar duas linguagens diferentes ao tratar do problema da definição de verdade: a primeira linguagem é "a de que se fala" (a linguagem-objeto) e a segunda é a linguagem "pela qual falamos" da primeira (a metalinguagem). A definição de verdade que buscamos se aplica às orações da linguagem-objeto, mas a construção dessa definição de verdade será feita no interior da metalinguagem.

Retomemos a convenção (T):

(T) $X$ é verdadeira se, e apenas se, $p$.

A definição, e todas as equivalências por ela implicadas, devem ser formuladas na metalinguagem. $O$ símbolo $p$, que aparece em $(T)$, no entanto, representa uma sentença arbitrária da linguagem-objeto e, em conseqüência, toda sentença que exista na linguagem-objeto deve também existir na metalinguagem. A conseqüência disso é que a linguagem-objeto deve ser parte da metalinguagem. Por isso, se alguém assume que a linguagem é meio universal, deve assumir também que é impossível uma metalinguagem qualquer que contenha, como parte, a linguagem. Logo, a metalinguagem é uma impossibilidade e nenhuma definição semântica de verdade é possível.

Em consequência, qualquer teoria semântica, no sentido que vimos definindo, necessariamente deve assumir a perspectiva em que a linguagem é entendida como um cálculo. 


\section{Significado e verdade}

Em que sentido a definição tarskiana de verdade determina uma semântica para as línguas naturais? O que as línguas naturais têm a ver com a noção de verdade?

As questões acima são frequientes entre os estudantes que se iniciam na semântica de modelos e é necessária uma justificativa da abordagem dos significados das expressões lingüísticas em termos de valores de verdade. de Tarski

O procedimento básico é o seguinte: assume-se a definição de verdade

(T) X é verdadeira se, e apenas se, $p$.

e faz-se a seguinte modificação:

(S) $X$ significa $p$.

O raciocínio é o seguinte: (i) assume-se que estamos diante de duas linguagens (uma linguagem-objeto e uma metalinguagem); (ii) assume-se que p nos dá o conjunto de condições necessárias e suficientes para a determinação da verdade de X; (iii) identificam-se as condições de verdade de uma sentença $\mathrm{X}$ com o seu significado.

Voltemos ao exemplo de Tarski. A sentença "A neve é branca" ou é verdadeira ou é falsa. Ela será verdadeira se, no mundo, a neve for branca e será falsa se a neve não for branca. Assim, a brancura da neve é condição, necessária c suficiente, para a verdade da sentença "A neve é branca". Em outras palavras, para que a sentença "A neve é branca" seja verdadeira é preciso que a neve seja branca e basta que a neve seja branca. Seja a sentença "A neve ć branca" a sentença $X$ de uma dada linguagem $\mathrm{Ll}$; vamos usar outra linguagem, L2, para expor as condições necessárias e suficientes da verdade da sentença $X$. Na definição de verdade de Tarski, basta repetir a sentença $X$, sem as aspas, como p. para termos as condições de verdade de X. É preciso ficar claro, no entanto, que $X$ e p pertencem a linguagens distintas. $X$ é a sentença cujas condições de verdade (cujo significado) queremos expor e p é a expressão da outra linguagem que expõe as condições de verdade de $\mathrm{X}$.

Há duas questões a discutir aqui. Comecemos nos perguntando se é razoável identificar condições de verdade a significado.

A resposta deverá ser positiva. Só saberemos quais são as condições de verdade de uma determinada sentença se conhecermos seu significado e, uma vez que conhecemos o significado de uma sentença, sabemos quais são suas condições de verdade.

É necessário ter em mente que saber as condições de verdade de uma sentença não é igual a saber se a sentença é verdadeira ou falsa: muitas vezes 
sabemos em que condições a sentença é verdadeira mas não sabemos se é ou não verdadeira. Por exemplo, suponhamos a seguinte sentença:

(5) O número de folhas de grama no jardim é ímpar.

As condições de verdade da sentença são facilmente estabelecidas: a sentença será verdadeira se, e apenas se, o número de folhas de grama no jardim for ímpar. Agora, a verdade ou falsidade da sentença vai depender de contarmos as folhas de grama, o que certamente não é uma tarefa facilmente exequiível. Então, podemos saber quais são as condições de verdade da sentença sem sabermos se ela é verdadeira ou não. $O$ que é preciso ficar claro é que o significado da sentença está sendo igualado às condições de verdade da sentença e não à sua verdade ou falsidade.

Observe-se que diante de uma sentença do português como

(6) A loba ${ }^{2}$ abichornou os borregos.

não só não sabemos se a sentença é verdadeira ou falsa como não sabemos em que condições ela seria verdadeira. E isso é assim porque não sabemos o que a sentença significa. Basta, no entanto, darmos uma olhada no dicionário e descobrirmos que loba é "um tipo de tumor", que borrego é "a cria da ovelha" e que abichornar é "tornar desanimado", para que saibamos quais são as condições de verdade da sentença:

(7) "A loba abichornou os borregos" é verdadeira se, e apenas se, o tumor deixou os cordeirinhos desanimados.

Podemos inclusive saber que determinada sentença não tem valor de verdade (i.e., não é nem verdadeira nem falsa) e mesmo assim sabermos quais são suas condições de verdade. Por exemplo,

(8) A primeira mulher a pisar na Lua é loira.

Esta sentença não tem valor de verdade porque nenhuma mulher ainda pisou na Lua. No entanto, as condições de verdade da sentença são claras: a sentença será verdadeira se, e apenas se, a primeira mulher a pisar na Lua for loira. Assim, parece razoável identificar o significado de uma sentença às suas condições de verdade.

A segunda questão a merecer discussão tem a ver com a natureza da metalinguagem utilizada para expor as condições de verdade de uma sentença da linguagem-objeto. Tarski usou um caso limite em que tanto a linguagem-objeto quanto a metalinguagem são, aparentemente, a mesma linguagem. Mas não precisaria ser assim. Poderíamos, por exemplo, usar o inglês, ou o latim, como

2 Pronuncia-se lóba, com na /ə/ tônica. 
metalinguagem para o estabelecimento das condições de verdade das sentenças do português. Certamente não haveria vantagem em proceder assim, já que o inglês (e o latim) são línguas ao menos tão complexas quanto o português; a única vantagem, talvez, seria uma maior dificuldade em confundir linguagem e metalinguagem, impedindo a derivação de paradoxos. Por outro lado, talvez obtivéssemos vantagens se as condições de verdade das sentenças da linguagem-objeto fossem estabelecidas de outra forma que não numa linguagem ordinária. Possivelmente chegaríamos a resultados melhores se nossa metalinguagem fosse uma espécie de linguagem que procurasse reproduzir, da forma mais transparente possível, a "organização" do próprio mundo em que as expressões lingüísticas se interpretam. É exatamente isso que se quer obter com a noção de modelo.

\section{Modelos}

Mas o que é, na verdade, um modelo? De modo geral, o termo modelo designa uma representação esquemática de um objeto ou de um sistema concreto, i.e., uma representação simplificada de uma realidade complexa que objetiva facilitar a compreensão desta última. Para uma teoria formal, no entanto, o modelo é uma estrutura (um conjunto de objetos atômicos com propriedades e relações definidas sobre esses objetos) construída de tal forma que os teoremas da teoria resultam verdadeiros quando interpretados nos elementos da estrutura. Em outras palavras, modelo é o sistema em que se cumpre o que diz a teoria.

Pensemos nas expressões de uma língua (as sentenças, em particular) como teoremas de uma teoria. Assim, a sentença "a neve é branca" seria um "teorcma" da língua portuguesa. Em que modelos esse teorema se cumpre? Ora, a resposta é óbvia: em todos os modelos em que a neve é branca. Dessa forma, todos os sistemas (todas as estruturas) que supõem a brancura da neve podem ser considerados modelos adequados para a interpretação da sentença "a neve é branca". Daí podermos dizer que uma sentença determina um conjunto de modelos, i.e., para cada sentença há um conjunto de modelos que apresentam as condições de verdade da sentença. Para a sentença "a neve é branca", todos os modelos de mundo em que a neve é branca são adequados; para a sentença "a neve é vermelha" apenas são adequados os modelos em que a neve seja vermelha.

Como vimos acima, a tarefa da semântica é relacionar as expressões linguiísticas a "coisas" não-lingüísticas. Vimos também que essas "coisas não- 
linguísticas" devem ser estruturadas num sistema de algum tipo. Ora, se a semântica vai justamente trabalhar com a relação entre dois sistemas: um sistema lingüístico e, digamos, o mundo (um sistema onde se cumprem as condições de verdade de todas as sentenças da língua) - ambos imensamente complexos -, precisamos de modelos para dar conta deles e de sua relação.

A estruturação do pólo lingüístico da relação semântica (a descrição, ou modelagem, do sistema linguíístico, em outras palavras) vai ser obtida na sintaxe (na teoria sintática) da língua natural.

A estruturação do pólo não-lingüístico da relação semântica implica levantarem-se hipóteses ontológicas. Descrever o mundo como um sistema implica dizer o que existe e como se relacionam essas coisas que existem.

Num certo sentido, essa tarefa não caberia ao lingüista (enquanto lingüista), mas ao filósofo.

É possível, no entanto, que enquanto lingüistas, levantemos hipóteses sobre a natureza e organização do mundo, a partir das necessidades interpretativas que a linguagem nos impõe. Em outras palavras, para dar conta do significado de uma sentença como "a neve é branca" o lingüista precisa de um mundo em que haja neve e em que essa neve apresente a "qualidade" de ser branca, ou seja, a sentença determina, ao menos em parte, características que devem ser satisfeitas pelos modelos de mundo que se pretendam adequados. De certa forma, estou invertendo a direção da flecha de determinação: ao invés de dizer que há um mundo e que a linguagem fala dele, estou dizendo que há uma linguagem e que precisamos estabelecer como seria o mundo para que a linguagem se interpretasse. Isso não significa, no entanto, que eu esteja assumindo uma posição anti-realista, uma posição em que o mundo não existe previamente à linguagem. Pode significar, entretanto, que eu esteja propondo, hipoteticamente, como sempre, que a linguagem e o mundo se constroem mutuamente (a linguagem determina o mundo em que se interpreta), o que me parece bastante razoável.

O procedimento dos semanticistas tem sido o de propor modelos bastante simples do mundo e tentar interpretar neles o maior número possível de sentenças das línguas naturais. $\mathrm{Na}$ medida em que os modelos se revelem inadequados (e ser inadequado faz parte da natureza desses modelos), eles vão sendo substituídos por modelos mais complexos. Trata-se, então, de obter uma série de modelos, cada vez mais sofisticados, que se aproximem do mundo, tal como concebido pelas línguas naturais. Mas, como é que se constrói um modelo de mundo? 


\section{Modelos como "conhecimento de mundo"}

Deixando de lado o caso meio óbvio da construção de um modelo teórico por um semanticista interessado em interpretar algumas expressões (o modelo é um construto teórico, apenas), parece-me que os modelos "reais", que poderíamos dizer constituírem o "conhecimento do mundo" dos falantes, constroem-se pouco a pouco a partir das experiências que as crianças vão tendo com a linguagem e com o mundo que as cerca. Como as experiências das crianças, seja com a linguagem que recebem de seus pais, seja com o mundo que as cerca, seja com o mundo de que tomam conhecimento pela escolarização, pelos meios de comunicação etc., são únicas, podemos dizer que cada criança, no processo de aquisição da linguagem e do conhecimento, constrói um modelo de mundo diferente de todos os outros. Dessa forma, na medida em que o significado se dá na relação com o modelo, no limite, cada criança atribui um significado particular às expressões de sua língua materna, diferentes dos significados atribuídos pelos outros.

A questão, então, passa a ser a de justificar as coincidências na atribuição de significados às expressões e não a de justificar as divergências. As coincidências evidentes de sentido, quer me parecer, devem ser explicadas a partir da consideração de um caráter social do significado. Obviamente, crianças com experiências semelhantes construirão modelos semelhantes. Assim, as crianças de uma mesma família não só falarão de forma semelhante (haverá menos variação entre seus idioletos) como "verão o mundo" de forma semelhante, atribuindo os mesmos significados (ou significados muito semelhantes) às expressões.

Parece evidente que essa posição nos remete diretamente a uma noção de variação semântica em quase tudo semelhante à noção de variação lingüística comumente usada pelos sociolingüistas. $O$ que existe é o idioleto e uma língua é um feixe de variações também no que diz respeito ao significado das expressões. Parece evidente, também, que essa posição deixa a semântica de valor de verdade na proximidade das teorias que dizem que o significado é resultado da história dos usos das expressões. Ao mesmo tempo, no entanto, atribui alguma estabilidade ao modelo de mundo "idioletal". 


\section{Conclusão}

Não creio que interesse ao semanticista a descrição do sistema de significados presente num idioleto. A mim não interessa, ao menos. Não creio que se possa fazer, de forma interessante, ciência do particular. Podemos, então, abstrair das diferenças entre os inúmeros sistemas particulares de relações entre as expressões e os modelos de mundo e pensarmos na construção de uma espécie de "arquitetura geral" que pudesse ser projetada nos sistemas reais de forma a "organizá-los", o que é, afinal, um procedimento absolutamente trivial nas ciências naturais: trata-se de forma sistemática o geral e deixa-se o idiossincrático para estudos locais posteriores.

O procedimento da semântica, então, é o de construir, hipoteticamente, um modelo do mundo (dizendo o que existe e como essas coisas que existem se relacionam entre si) e estabelecer algum mecanismo, formal de preferência, que relacione sistematicamente as expressões da linguagem a essas "coisas" existentes no modelo.

As questões mais interessantes, em conseqüência, passam a ser as questões relacionadas ao aspecto "ontológico" dos modelos. Poderíamos interpretar as expressões do português num modelo constituído de entidades atômicas que se relacionam pelas regras de uma teoria de conjuntos? Precisaríamos postular a existência de propriedades como primitivos do modelo? Qual deveria ser a noção de indivíduo adequada à interpretação das expressões da língua natural: indivíduo como entidade atômica ou como uma mereologia? Precisaríamos postular a existência de "tempos" no modelo? E os "tempos" seriam pontos localizados num contínuo ou seriam intervalos? Que coisas no modelo se alterariam em função do tempo e que coisas não se alterariam? Existem os "eventos"? Se existem, como poderíamos tratá-los?

Enfim, diante do semanticista se abre um vasto campo de investigação, em muitos aspectos parecido com o da investigação filosófica, em que a linguagem é o guia.

\section{RESUMO}

O texto pretende chegar a uma conceituação adequada de "semântica formal", esclarecendo a noção de "significado" suposta e suas relações com outras áreas (e/ou abordagens) do estudo da linguagem humana. A partir da noção de "verdade como correspondência" e da noção de "modelo de interpretação", procura-se esboçar a proposta 
BORGES NETO, J. Semântica formal

de uma teoria semântica, rigorosamente formal, que se aproxima sensivelmente das teorias da enunciação e das teorias do discurso.

Palavras-chave: semântica, semântica formal, semântica de modelos

\begin{abstract}
This paper attempts to propose an adequate definition for "Formal Semantics" by clarifying the concept of "meaning" and its relations with other fields (and/or approaches) of human language study. Departing from the notions of "truth as correspondence" and "interpretation model," a proposal for a rigourously formal semantic theory is sketched, i.e., one which noticeably comes within the scope of enunciation and discourse theories.
\end{abstract}

Key-word: semantics, formal semantics, model semantics

\title{
REFERÊNCIAS
}

BORGES NETO, J. 1998. Fundamentos de semântica formal. Curitiba, 1998. Tese de Professor Titular. Inédita.

HINTIKKA, J. Freges hiden semantics. Revue Internationale de Philosophie, v. 33, p. 716-722, 1979.

JACKENDOFF, R. Semantics and cognition. Cambridge, Mass.: MIT Press, 1983.

TARSKI, A. La concepción semántica de la verdad y los fundamentos de la semántica. Buenos Aires: Nueva Visión, 1972. 